\title{
RESOLUÇÃO DE CONFLITOS ANATEL: A PROBLEMÁTICA DA INTERCONEXÃO DE REDES
}

\section{ANATEL CONFLICTS RESOLUTION: THE NETWORK INTERCONNECTION PROBLEM}

\author{
Catarina Ribeiro Franco \\ Mestranda em Direito da Sociedade da Informação e bacharel em Direito pelo Centro \\ Universitário das Faculdades Metropolitanas Unidas. Especialista em Propriedade \\ Intelectual pela Fundação Getúlio Vargas Escola de Direito de São Paulo (FGV LAW); \\ Professora do curso de Direito da Kroton Educacional-Campus Anhanguera Osasco; e das \\ matérias de Direito da Fundação Escola Nacional de Seguros - FUNENSEG. \\ E-mail: catarinaribeirofranco@gmail.com.
}

Recebido em: 06/11/2016

Aprovado em: 24/03/2017

Doi: $10.5585 /$ rdb.v17i7.531

RESUMO: As telecomunicações exercem função essencial na sociedade da informação e, consequentemente, no cotidiano social. As mudanças tecnológicas e o surgimento de serviços cada vez mais diversificados e modernos promovem uma discussão global quanto à necessidade de mudanças políticas estruturais e legais no setor. Entre os países que optaram por amplos processos de privatização de serviços básicos, como é o caso brasileiro, verificou-se uma convergência para a criação de órgãos de regulação que pudessem conferir maior autonomia ou poderes aos já existentes, incentivando e fortalecendo as agências reguladoras. No caso nacional, as agências reguladoras nascem de uma conjuntura político-ideológica de desestatização articulada durante a década de 1990 e inspirada no modelo norte-americano. Neste estudo, destaca-se a Agência Nacional de Telecomunicações - ANATEL, criada com o intuito de flexibilizar o setor de telecomunicações, que atualmente encontra dificuldades para democratizar a comunicação no país e defender os direitos dos consumidores. Discute-se ainda a atuação da agência na resolução dos conflitos de interesse gerados no processo de interconexão de redes entre concessionárias, fator que impacta diretamente no valor e na qualidade dos serviços de telecomunicações oferecidos aos usuários.

Palavras-chave: resolução; conflitos; ANATEL; interconexão; redes.

ABSTRACT: Telecommunications play an essential role in the information society and, consequently, in everyday social life. The technological changes and the emerging of increasingly diversified and modern services promote a global discussion about the need for structural and legal political changes in the sector. Among countries, such as Brazil, which have choosen for broad basic services privatization processes there was a convergence towards the creation of regulatory bodies that could give greater autonomy or powers to existing ones, encouraging and strengthening regulatory agencies. In the national case, the regulatory agencies come from a political-ideological conjuncture of privatization articulated during the 1990s and inspired by the North American model. In this study, the National Telecommunications Agency ANATEL, was created to flexibilize the telecommunication sector, which is currently struggling 
to democratize communication in the country and defend the consumers' rights. It also raises the discussion about the agency's actions in resolving conflicts of interest generated in the networks interconnection between concessionaires, an issue that directly underlies the value and quality of telecommunications services offered to users.

Keywords: resolution; conflicts; ANATEL; interconnection; networks.

SUMÁRIO: Introdução; 1. ANATEL - Agência Nacional de Telecomunicações; 2. A mediação e a arbitragem da ANATEL como alternativa para a resolução de conflitos no setor de telecomunicações; 3. A problemática dos acordos de interconexão de redes no Brasil; 4. A atuação da ANATEL nos conflitos e negociações de interconexão de redes; Conclusão; Referências Bibliográficas.

\section{INTRODUÇÃO}

O fenômeno da regulação midiática e o modelo de instituições regulatórias surge no século XIX, nos Estados Unidos e na Inglaterra ${ }^{1}$. Entretanto, no Brasil ${ }^{2}$, é somente a partir da segunda metade da década de 1990 que tal fenômeno incorpora-se ao ordenamento jurídico do pátrio com a aprovação da Emenda Constitucional $n^{\circ}$ 8, de $1995^{3}$, que alterou o artigo 21 da Constituição Federal vigente. Tal marco viabilizou a criação de agências reguladoras com o intuito de controlar a atuação de empresas privadas que passaram a desempenhar serviços públicos, a exemplo da ANATEL - Agência Nacional de Telecomunicações.

Assim, o modelo estatal brasileiro, antes concentrado na produção de bens e prestação de serviços próprios ao modelo de gestão pública burocrática ${ }^{4}$, cedeu lugar ao chamado Estado Regulador. Essa nova concepção de Estado transformou as decisões institucionais, introduzindo a ideia do que hoje se conhece como Administração Pública Gerencial ${ }^{5}$. O poder político

\footnotetext{
${ }^{1} \mathrm{Na}$ Europa, após a Segunda Guerra Mundial, foram criadas políticas econômicas de nacionalização, também denominadas de coletivização, estatização e socialização, baseadas em um rígido controle das atividades no setor por parte do Estado (DASSO JUNIOR, 2012, p. 1). Tais políticas possuem como principais aspectos: a eficiência no uso e na alocação dos recursos (controle de preços, quebra de monopólios privados etc.), a democracia econômica mediante a redistribuição de recursos, o pleno emprego, a diminuição da inflação, o reequilíbrio na balança de pagamentos e o crescimento econômico (apud MATTOS, 2002, p. 44-5). Nos Estados Unidos, a forma de intervenção do Estado na economia é baseada, desde o final do século XIX, na regulação de mercados. Mas é fundamentalmente a partir da década de 1930, com o New Deal, que o controle do desenvolvimento econômico por meio de agências reguladoras passa a ter destaque. No período, o objetivo principal era evitar que os monopólios privados fizessem uso excessivo de seu poder, eliminando possíveis concorrências. Posteriormente, o Estado preocupar-se-á em corrigir problemas de informação imperfeita, preservando os consumidores e buscando maior equidade distributiva no setor (DASSO JUNIOR, 2012, p. 3).

2 "O fenômeno regulatório que atingiu o Brasil não foi um caso isolado, devendo ser reconhecido como pertencente às transformações que sofreu a América Latina na mesma época e como consequência das mudanças que atingiram o mundo, especialmente EUA e Europa, a partir do final da década de 1970” (DASSO JÚNIOR, 2012, p. 1).

${ }^{3}$ Analisam-se, neste estudo, as transformações no setor das telecomunicações posteriores à Emenda Constitucional $\mathrm{n}^{\circ}$ 8, de 1995, que permitiram a exploração do mercado mediante autorização, concessão ou permissão dos serviços de telecomunicação, atividades que antes eram monopólio do Estado.

${ }^{4}$ Com base no contexto da Revolução Francesa, Max Weber desenvolveu a "Teoria de Burocracia na Administração" (CHIAVENATO, 2003, p. 254-5). Nesta, a burocracia é articulada e entendida como ferramenta capaz de diferenciar os interesses público e privado, aspectos corriqueiros vivenciados em administrações patrimonialistas definidoras das monarquias absolutistas daquele período histórico. Desse modo, a hierarquização do funcionamento do Estado, galgada nos princípios de qualidade, agilidade e eficiência, inaugura o ideário do Estado moderno e intervencionista. Tal modelo de administração burocrática foi adotado pela Constituição Federal de 1988 (BRESSER-PEREIRA, 1996, p. 4).

5 No caso brasileiro, a adoção da "Administração Pública Gerencial" surge como discurso político decorrente da estagnação da renda per capita e da alta inflação no período histórico entre 1979 e 1994. Esse modelo gerencial de Estado está alicerçado nas políticas neoliberais insurgentes no final do século XX. Tem como principal objetivo

Revista de Direito Brasileira | São Paulo, SP | v. 17 | n. 7 | p. 203 - 220 | Mai./Ago. 2017
} 
neoliberal, viabilizador dessa mudança, firma o entendimento de que esse modelo democratiza a administração pública, possibilitando maior participação dos cidadãos na tomada de decisões. Porém, contrariamente, é por meio da prática do modelo gerencial que o Estado se desonera do acúmulo de responsabilidades advindas do modelo burocrático.

O termo agência fora importado do direito estadunidense (DI PIETRO, 2002; MANEZELLO, 2002; MARQUES NETO, 2005; MAZZA, 2005), entretanto, com sentido mais restrito, pois

[...] abrange qualquer autoridade do governo dos Estados Unidos, esteja ou não sujeita ao controle de outra agência, com exclusão do Congresso e dos Tribunais. [...] Nos Estados Unidos, falar em Administração Pública significa falar nas agências, excluída do conceito a própria Presidência da República (DI PIETRO, 2002, p. 398).

No direito brasileiro, as agências reguladoras são autarquias que vigoram em regime especial. Criadas para equilibrar determinados setores da economia, elas exercem tarefas tipicamente do Estado. Assim, conceitualmente, as agências integram a Administração Pública Indireta, "sendo criadas para realizar as tradicionais atribuições da Administração Direta, na qualidade de Poder Público concedente, nas concessões, permissões e autorizações de serviços públicos" (MORAES, 2002).

No Brasil, compreendendo o regime de governo como "democracia em processo", bem como o contexto de sociedade da informação, questiona-se se as agências reguladoras contribuem para a consolidação democrática (FIORATI, 2004). Sabendo-se dos diversos instrumentos democráticos articulados teoricamente na concepção das agências, disponíveis em seus processos decisórios, pesquisou-se os métodos consensuais de resolução de conflitos utilizados pela Agencia Nacional de Telecomunicações - ANATEL, bem como se estes contribuem para o fomento da pretendida participação democrática da sociedade. Mediação, conciliação, arbitragem e consulta popular são procedimentos propagados como ferramentas democráticas porque utilizam o protagonismo das partes na resolução dos conflitos, ampliando o sentimento de inclusão social nos cidadãos. Todavia, na prática, tais processos parecem ser pouco conhecidos por seus titulares quando utilizados, pois apresentam pouca eficácia.

Nesse sentido, de acordo com os discursos vigentes, uma efetiva atuação da ANATEL na promoção dos meios alternativos de resolução de conflitos poderia confirmar o caráter democrático que a administração pública pretende inferir na legislação do setor de telecomunicações, confirmando a pretendida harmonização com os fins democráticos do Estado de Direito e adequando-a à previsão constitucional.

O setor de telecomunicações no Brasil é marcado por diversas fases de transição, considerando os discursos da necessidade de acompanhamento das mudanças tecnológicas emergidas principalmente no final do século $\mathrm{XX}$, oriundos do contexto da sociedade da informação. O Estado teve função essencial nesse processo, influenciando a regulamentação e as negociações próprias ao setor. Após a quebra do monopólio estatal, promovida pelo governo Fernando Henrique Cardoso, o Ministério das Comunicações confirmou, por meio de portarias, a participação do setor privado nas atividades de telecomunicações e delineou os regimes de concessão, permissão e autorização a empresas privadas. Porém, reafirmou o controle estatal no setor pelo exercício do poder de polícia, característicos do Estado Gerencial (FIORATI, 2004).

A ANATEL é criada nos termos da EC no 8/95, com a Lei $n^{\circ}$ 9.472/97, Lei Geral de Telecomunicações - LGT, como órgão regulador do serviço de telecomunicações. Idealizada

reduzir a máquina estatal e, por consequência, as atribuições do Estado para o mínimo essencial, isto é, delegando a ele apenas o exercício do poder de polícia, as atividades jurisdicional e legislativa, a manutenção da previdência e alguns aspectos da assistência social. No Brasil, a reforma gerencial é iniciada a partir de 1995 (BRESSERPEREIRA, 1996, p. 2; 6). 
para ser agência mediadora, fiscalizadora e reguladora, intervindo como órgão conceitualmente independente nas negociações e nos conflitos entre as empresas concessionárias e também nos conflitos destas com os usuários. A normatização e a comunicação das atividades típicas da agência se dá basicamente por meio da edição de planos e regulamentos do setor de telecomunicações (FIORATI, 2004).

O processo de privatização do setor de telecomunicações culminou com o leilão das empresas do Sistema TELEBRAS, ocorrido em 1998, que rendeu R\$22,08 bilhões aos cofres públicos (NOVAES, 2000, p. 152). Foi no contexto posterior às privatizações que as operadoras e a ANATEL passaram a conviver, tornando frequentes as negociações e o desenvolvimento de políticas entre si. Em 2003, com a abertura formal do mercado, as operadoras de telefonia passaram a cumprir, ao menos em termos protocolares, com as metas de universalização e qualidade estabelecidas pela ANATEL incialmente (NOVAES, 2000).

O período de transição de um modelo estatal para o de competição, somado ao amplo e rápido desenvolvimento das novas tecnologias da informação e comunicação - TIC's, geraram importantes modificações no setor de telecomunicações no país. Passados quase 20 anos, tais fatos ainda promovem discussões sobre o papel da agência reguladora frente aos interesses dos consumidores, já que frequentemente ela é questionada por restringir a participação popular em seus processos e também pela falta de transparência em sua atuação junto às empresas concessionárias e a sociedade (VARELLA, 2010).

Se de um lado a criação das agências reguladoras, na vigência do governo Fernando Henrique Cardoso, promoveu investimentos econômicos privados em telecomunicações, possibilitando alguma ampliação e modernização dessa infraestrutura no país, de outro, proporcionou a apropriação desses mesmos bens públicos aos investidores privados, estabelecendo uma zona de conflito entre os interesses oriundos das políticas governamentais de situação aliadas aos das empresas de telecomunicações, e também a disponibilização, por parte do governo, de interesses relativos à coletividade sem que a questão fosse minimamente submetida a algum tipo de consulta popular ou debate com a sociedade civil.

Tal cenário evidenciou-se na gestão seguinte, em fevereiro de 2003, quando o à época presidente Luiz Inácio Lula da Silva iniciou discussão com empresas do setor, além da ANATEL e ANEEL, a respeito da revisão das tarifas telefônicas e de energia. Após a primeira reunião ministerial que visou examinar o assunto, deflagrou-se intenso debate público entre Governo Federal e as autarquias, tendo declarado o então presidente que "[...] as agências reguladoras mandavam no país" (Folha de S.Paulo, Brasil, 20 fev. 2003). Suas fortes críticas argumentavam que tais entidades não se prestavam a promover um amplo debate sobre os aumentos de tarifas do setor sequer com o Governo e não agiam no sentido de regulação dessas relações, e sim atuavam em parceria com as empresas privadas, desprezando a negociação com o nova gestão federal e a sociedade civil. Ainda nesse sentido, Lula afirmara que tomava conhecimento dos reajustes das tarifas via noticiosos, e não por meio do debate político que deveria ser sugerido e intermediado pelas agências. Tal embate revelou a disputa entre o então novo governo e as agências, cujos dirigentes deviam seus mandatos ao governo anterior, conforme destaca Gustavo Binenbojm:

Se, de uma parte, a criação de agências reguladoras dotadas de acentuado grau de autonomia servia ao bom propósito de desestruturar os chamados "anéis burocráticos" existentes nos Ministérios, de outra parte, o mandato fixo de seus dirigentes e seu compromisso técnico sinalizavam ao mercado o compromisso do próprio país de proteger o direito de propriedade dos investidores e garantir o cumprimento fiel dos contratos celebrados ao cabo dos processos de privatização e desestatização (BINENBOJM, 2005, p. 4).

Durante esse debate político, inseriu-se na mesma pauta a problemática dos contratos de interconexão de redes em telecomunicações. Tais pactos são obrigatórios e visam garantir a 
prestação dos serviços de telecomunicações aos usuários sem que haja qualquer interrupção do processo como um todo, tendo em vista a essencialidade do serviço público e a consequente responsabilidade da administração face à população. Por isso o tema é tratado na Lei Geral de Telecomunicações - LGT (Lei $n^{\circ}$ 9.472/97) e no Regulamento Geral de Interconexão - RGI (Resolução 410/2005 da ANATEL). Essas normas reafirmam o princípio constitucional da livre concorrência aplicado às empresas concessionárias dos serviços de telecomunicações, consignando ainda garantias à população quanto ao acesso desse serviço essencial em condições adequadas e a preços razoáveis.

Todavia, os contratos de interconexão de redes são pactos comerciais estabelecidos na esfera privada entre operadoras, elas mesmas acordando a remuneração pelo uso da infraestrutura. A ANATEL não necessariamente intervém nesse processo, ou só o faz quando existe litígio referente aos valores discutidos pelas concessionárias. Mesmo que a agência estabeleça parâmetros de precificação por meio de regulamentações, tais consignações dificilmente abrangem a complexidade das negociações ou são capazes de abarcar efetiva repressão à cobrança de valores abusivos aos usuários, conforme determina a legislação sobre o assunto. Nesse sentido,

[...] o que se vê no Brasil é que as operadoras aplicam o valor máximo regulamentado, não havendo então a negociação durante a fase de estabelecimento de contrato de interconexão entre as partes. Apesar disso, existem conflitos entre as operadoras que são mediados pela Anatel (PEREIRA et al, 2007, p. 2-3).

No presente trabalho, foram estudados contratos de interconexão de redes para analisar a atuação da ANTEL como mediadora na resolução de conflitos do setor de telecomunicações. Para abordagem do tema, procedeu-se ainda os seguintes recortes: (i) análise da atuação da ANATEL nos acordos de interconexão de redes de telefonia fixa no contexto da flexibilização das telecomunicações do Brasil; (ii) verificação dos poderes da ANATEL com relação ao setor de telefonia fixa; e (iii) estudo sobre a atuação da ANATEL no acordo de interconexão realizado entre a Embratel e a Telefônica, primeiro marco relativo à questão de interconexão de redes de telefonia.

\section{ANATEL - AGÊNCIA NACIONAL DE TELECOMUNICAÇÕES}

No cenário nacional das telecomunicações, fatores como a globalização da economia, o contínuo e veloz aperfeiçoamento das tecnologias comunicacionais experimentado entre o séculos XX e início do XXI, a aceleração das mudanças no mercado e o consequente surgimento de novas necessidades dos consumidores redimensionaram o setor, sendo ele, inclusive, um dos objetos do GATS (General Agreement on Trade in Services) ou, em português, Acordo Geral sobre Comércio de Serviços - AGCS, encabeçado pela Organização Mundial do Comércio OMC (FIORATI, 2004, p. 96). Por força deste, cada um dos Estados-membros obrigou-se a assegurar aos prestadores de serviço de qualquer outro Estado-membro acesso às suas redes públicas de transporte, o que implicou na interconexão de circuitos privados. O Brasil aderiu a essa lista por meio do Protocolo 4/976 (FIORATI, 2004).

\footnotetext{
${ }^{6}$ O General Agreement on Trade in Services - GATS, articulado pela Organização Mundial do Comércio - OMC, e que substituiu o General Agreement on Tariffs and Trade - GATT na tarefa de fiscalizar e regulamentar o comércio internacional, é parte integrante da "Ata Final que incorpora os Resultados das Negociações Comerciais Multilaterais da Rodada Uruguai". No Brasil, a Ata Final foi promulgada pelo Decreto n ${ }^{\circ} 1.355$, de 30 de dezembro de 1994. Nos termos desse acordo, cada um dos Estados-Membros obrigou-se a assegurar aos prestadores de serviço de qualquer outro Estado-Membro acesso às suas redes públicas de transportes de telecomunicações e serviços, permitindo sua utilização de modo não discriminatório. Isso significa que os prestadores de serviços dos países signatários desse

Revista de Direito Brasileira | São Paulo, SP | v. 17 | n. 7 | p. 203 - 220 | Mai./Ago. 2017
} 
A quebra do monopólio das telecomunicações no país, que deu status constitucional ao órgão regulador das telecomunicações, eliminou a exclusividade na exploração dos serviços públicos a empresas sob controle acionário estatal, permitindo sua privatização e tentando introduzir o regime de livre competição e iniciativa entre elas, conforme o artigo 170, incisos IV e V da Constituição Federal. Na prática, o Estado passou da função de provedor para a de regulador e fiscalizador dos serviços de telecomunicações.

A Lei $\mathrm{n}^{\circ}$ 9.295/1996 inaugurou, em sede infraconstitucional, um novo modelo de gestão das telecomunicações, ocupando-se basicamente da organização dos serviços de telecomunicações, a exploração do serviço móvel celular, serviço limitado e serviço de transporte de sinais de telecomunicações por satélite. Porém, foi somente por meio da Lei $n^{\circ}$ 9.472/97 - LGT, instituidora da ANATEL, que o novo modelo de gestão gerencial das telecomunicações se efetivou em padrões bastantes semelhantes ao órgão regulador americano (FIORANTI, 2004).

A Agência Nacional de Telecomunicações foi concebida para ser uma autarquia administrativamente independente, pertencente à administração pública indireta, financeiramente autônoma e não subordinada hierarquicamente a nenhum órgão de governo, segundo artigo $8^{\circ}, \S$ $2^{\circ}$ e artigo $9^{\circ}$ da LGT. É a última instância administrativa, sendo que as decisões da ANATEL só podem ser contestadas judicialmente. Idealmente, suas minutas de atos normativos deveriam submeter-se a consulta pública, conforme o artigo 42 da LGT. Seus atos devem estar acompanhados por exposição formal de motivos que os justifiquem e, em determinados casos, devem ser promovidas audiências públicas para a manifestação presencial da sociedade. As atas de reuniões e os documentos relativos às decisões do Conselho Diretor e à atuação da ANATEL encontram-se disponíveis ao público na biblioteca da agência como uma das alternativas de dar publicidade e acesso sobre sua atuação à população.

Nesse sentido, a ANATEL também é responsável por procedimentos de solução de controvérsias entre os usuários e os agentes regulados e dos últimos entre si. Configura-se, portanto, em meio para a mediação de conflitos na busca de sintonizar os diversos atores envolvidos no setor das telecomunicações, caracterizado por sua crescente complexidade e pela especialização de suas tecnologias. É sua tarefa promover a mediação ativa dos interesses dos operadores, usuários e do poder político, com o objetivo de assegurar o atendimento das parcelas mais vulneráveis da população. Esse poder é também conhecido como "quase judicial" e deve centrar-se no consensualismo em detrimento de decisões unilaterais (VENTURA; MARTINELLI, 2006).

Por tais motivos, a agência reguladora deve buscar assegurar a maior permeabilidade da atividade regulatória aos interesses da sociedade, possuindo mais capacidade de arbitramento desses interesses e se configurando em um novo tipo de autoridade estatal para o setor. Trata-se de um aspecto diferente da regulação estatal tradicional, desenvolvida em espaços tecnocráticos sem clara interlocução com a sociedade. A ANATEL possui autoridade negocial, ao invés de uma autoridade unilateral (VENTURA; MARTINELLI, 2006).

Entretanto a ANATEL, apesar de ser uma das agências mais bem avaliadas quanto à

acordo deverão dar acesso a qualquer rede pública de transporte de telecomunicações ou serviço oferecido dentro do território ou na fronteira de cada Estado-Membro. Para tanto, cada Estado-Membro comprometeu-se a permitir, por exemplo, a interconexão de circuitos privados, arrendados ou próprios, com redes públicas de transporte de telecomunicações de propriedade de outro prestador de serviço. Além disso, nenhum Estado-Membro poderá impor condições ao acesso e utilização das redes e serviços públicos de transportes de telecomunicações além do que seja necessário para, inter alia: (i) salvaguardar as responsabilidades dos provedores públicos das redes e serviços de transportes de telecomunicações, em particular sua capacidade de colocar à disposição do público em geral suas redes ou serviços; e (ii) assegurar o cumprimento dos compromissos consignados na lista negociada pelo EstadoMembro. O Brasil assinou recentemente a lista (Protocolo $\mathrm{n}^{\circ}$ 4/97) que consolida as ofertas dos 70 países que concordaram com a abertura de seus mercados de telecomunicações - esse protocolo tem eficácia pelo direito internacional, já que o país é signatário do acordo, operado desde 1998 em todos os serviços que a legislação brasileira já contemplava à época (CELLI, 1998, p. 156).

Revista de Direito Brasileira | São Paulo, SP | v. 17 | n. 7 | p. 203 - 220 | Mai./Ago. 2017 
procedimentalização formal (VALENTE, 2015), acumula críticas da sociedade civil devido às suas ações visivelmente voltadas para defesa dos interesses dos oligopólios das telecomunicações no Brasil, formado por poucas mas poderosas empresas privadas que detêm a maior parte das ações que controlam o setor. Tal aspecto abre precedentes para discussões da necessidade de novo marco regulador nas telecomunicações, da efetividade da democratização das comunicações no país e do monopólio da informação pelo chamado "quarto poder". Nesse sentido, afirma Flávia Lefèvre Guimarães (2012):

[...] a Anatel, para não fugir do script que tem seguido desde sua instalação, começa a falar da revisão do marco legal das telecomunicações pautando-se pelos interesses privados dos fortes grupos econômicos que atuam no setor. $\mathrm{O}$ foco da Anatel, por si só, já se revela ilegal. Primeiro porque caberia ao Ministério das Comunicações abrir os debates com a sociedade, a fim de definir novas políticas para o setor, como determinam os arts. 84 e 87 da Constituição Federal e art. 14, inc. III, da Lei 9.649/1998. Segundo porque, além de estar extrapolando os poderes que possui, a agência está sempre agindo ou deixando de agir de modo a garantir que a iniciativa privada se aproprie de bens públicos, como fez quando celebrou os contratos de concessão da telefonia fixa sem relacionar os bens reversíveis e os essenciais para a prestação deste serviço. $\mathrm{O}$ mais novo discurso é antecipar o fim das concessões de telefonia fixa e entregar para a iniciativa privada todo o acervo relacionado a este serviço junto com a preciosa rede, hoje 100\% digitalizada, contando com grande parte de fibra ótica, instalada em todo o país, com papel fundamental também para os serviços de telefonia móvel e banda larga.

Ao analisar a independência das agências reguladoras no Brasil em relação ao que ocorre nos Estados Unidos, Binenbojm destaca que

[...] embora o modelo da agência reguladora independente norte-americana tenha servido de inspiração ao legislador brasileiro, a sua introdução no Brasil serviu a propósitos distintos, senão opostos. De fato, enquanto nos estados Unidos as agências foram concebidas para propulsionar a mudança, aqui foram elas criadas para garantir a preservação do status quo; enquanto lá buscavam elas a relativização das liberdades econômicas básicas, como o direito de propriedade e a autonomia da vontade, aqui sua missão era a de assegurá-las em sua plenitude contra eventuais tentativas de migração por governos futuros $(2005$, p.6).

Passado o processo de privatização e desestatização das telecomunicações no Brasil, a conceitual autonomia das agências reguladoras parece perder força ante o desafio promovido pelas sucessões democráticas do Governo Federal. Hoje, os desafios referentes ao controle político, responsividade social e legitimidade democrática são temas que se entrelaçam com a discussão da autonomia técnica das agências e os mecanismos de controle político e jurídico associados ao seu exercício. Há muitos anos tais desafios são enfrentados pelos estadunidenses, já no Brasil a questão fora sublimada até a eleição de Lula (BINENBOJM, 2005).

\section{A MEDIAÇÃO E A ARBITRAGEM DA ANATEL COMO ALTERNATIVA PARA A RESOLUÇÃO DE CONFLITOS NO SETOR DE TELECOMUNICAÇÕES}

Uma das formas de resolução de conflitos relativos à jurisdição é a mediação. Esta pode ser definida por utilizar a gestão do problema pelas próprias partes, promovendo conjuntamente uma decisão mais célere, ponderada, eficaz e satisfatória (MORAES, 2002). A figura do mediador nesse processo é de grande importância, pois objetiva ajudar as partes a negociarem de 
maneira efetiva suas pendências (MARTINELLI; ALMEIDA, 1998). O mediador não tem como foco a resolução do problema, muito menos determina qualquer tipo de solução. Lewicki e Hiam (2003, p. 81) observam que a figura do mediador deve ser compreendida pelas partes em conflito como efetivamente imparcial, conquistando a confiança dos envolvidos também por ser um especialista na matéria objeto da questão.

Atualmente o tema ganha novo fôlego no país com o advento da Lei ${ }^{\circ} 13.105 / 2015$, novo Código de Processo Civil, que confere grande destaque à conciliação e mediação, dedicando uma seção inteira ao tema no Capítulo III, instituindo mecanismos fundamentais para a solução e preferência pela autorregulação dos conflitos. A solução consensual de conflitos administrativos instituída pelo diploma é considerada regramento inovador na esfera da Administração Pública, conforme estabelecido em seus artigos $174^{7}$ e $175^{8}$.

No âmbito das telecomunicações, a mediação administrativa ${ }^{9}$ foi alinhada à legislação nacional de criação das agências reguladoras como alternativa e tentativa de estabelecer efetivo equilíbrio jurídico da relação entre os agentes regulados. Foi inserida pela ANATEL em seu Regimento Interno - RI (Resolução $n^{\circ}$ 612/2013), e pela possibilidade os agentes regulados podem requerer à ANATEL sua atuação na mediação dos conflitos ou atribuição de direitos, sem a necessidade de recorrer ao Poder Judiciário.

Segundo o RI, a forma alternativa é conhecida como mediação administrativa de conflitos, isso porque o instituto possui previsão legislativa em que os titulares de relações jurídicas buscam solucionar o problema existente pela via direta ou por meio das vias administrativas da própria agência reguladora, observadas a possibilidade jurídica do pedido e uma possível vedação quanto à matéria em conflito.

No processo de mediação instaurado pela ANATEL, não existirão decisões unilaterais por parte da agência, já que a intenção baseia-se na autocomposição das partes, isto é, a ANATEL conduz a mediação sem proferir qualquer parecer final, restringindo-se tão somente a homologar o consenso reduzido a termo entre as partes. Durante esse processo as únicas intervenções realizadas pela agência dizem respeito aos preceitos expressos em seu regimento interno, e também quanto ao disposto na Lei Federal $n^{\circ} 9.784 / 1999$, que se refere ao processo administrativo dirigido à proteção dos direitos dos administrados e ao melhor cumprimento dos fins da Administração (MENEZELLO, 2002).

Outra possibilidade amplamente utilizada em conflitos oriundos das telecomunicações é a arbitragem, procedimento considerado mais comum que a mediação e que conta com a intervenção de uma terceira parte, imparcial ao processo de negociação e que profere decisão final resolutiva (MARTINELLI; ALMEIDA, 1998).

Tal ferramenta, que no direito privado também é conhecido como arbitragem civil ${ }^{10}$,

\footnotetext{
7 “Art. 174. A União, os Estados, o Distrito Federal e os Municípios criarão câmaras de mediação e conciliação, com atribuições relacionadas à solução consensual de conflitos no âmbito administrativo, tais como:

I - dirimir conflitos envolvendo órgãos e entidades da administração pública;

II - avaliar a admissibilidade dos pedidos de resolução de conflitos, por meio de conciliação, no âmbito da administração pública;

III - promover, quando couber, a celebração de termo de ajustamento de conduta."

8 “Art. 175. As disposições desta Seção não excluem outras formas de conciliação e mediação extrajudiciais vinculadas a órgãos institucionais ou realizadas por intermédio de profissionais independentes, que poderão ser regulamentadas por lei específica."

9 A mediação administrativa foi instituída pela ANATEL por meio da Resolução n ${ }^{\circ}$ 612, de 29 de abril de 2013. Importante frisar que a medição como ferramenta para soluções de conflitos gerais está prevista na atual Lei $\mathrm{n}^{\circ}$ 13.140, de 26 de junho de 2015, que dispõe sobre a mediação entre particulares como meio de solução de controvérsias e sobre a autocomposição de conflitos no âmbito da administração pública, alterando ainda a Lei $\mathrm{n}^{\circ}$ 9.469, de 10 de julho de 1997 , e o Decreto $n^{\circ} 70.235$, de 6 de março de 1972 , e revogando o $\S 2^{\circ}$, do art. $6^{\circ}$ da Lei $n^{\circ}$ 9.469, de 10 de julho de 1997.

${ }^{10}$ A arbitragem civil está prevista na Lei no 9.307/96 e é também mencionada pelo Código Civil, que faculta a introdução de cláusula compromissória para a solução de divergências, mediante a arbitragem nos contratos.
}

Revista de Direito Brasileira | São Paulo, SP | v. 17 | n. 7 | p. 203 - 220 | Mai./Ago. 2017 
permite que as partes litigantes escolham livremente um terceiro - chamado de árbitro, figura não pertencente ao Poder Judiciário - para que, em condições previamente estabelecidas, emita uma decisão com força definitiva e que em princípio não possa ser novamente questionada em juízo.

A arbitragem administrativa é outro meio alternativo para a resolução de conflitos regulados pela ANATEL, devendo tal instituto ser observado por suas peculiaridades, tendo em vista o contexto das telecomunicações. O primeiro destaque importante é que, ao contrário do que ocorre na arbitragem civil, o árbitro não é escolhido livremente pelas partes - a decisão arbitral cabe à ANATEL e é considerada como jurídico-administrativa. Por esse motivo, é passível de questionamento judicial posterior. A arbitragem conduzida pela agência reguladora realiza-se de duas possíveis formas: a primeira diz respeito à interconexão das redes, recorte do presente estudo, e é regida pelo RGI; a segunda refere-se aos demais temas, sendo conduzida pelo Regimento Interno da ANATEL (RI).

A primeira possibilidade de arbitragem administrativa é utilizada pela agência em litígios cuja matéria de aplicação e interpretação da regulamentação versem sobre as negociações dos contratos comerciais de interconexão de redes de telecomunicações. Nesse caso, a arbitragem é feita por uma comissão estabelecida por procedimento público da agência. Seu presidente nomeia três membros que atuarão como árbitros, sendo indispensável o tratamento confidencial às questões. $\mathrm{O}$ procedimento de arbitragem nesse contexto só não será possível caso a problemática envolva risco à segurança do país ou prejuízo para qualquer uma das partes. A deliberação dar-se-á por maioria, podendo o árbitro que divergir reduzir a termo motivado seu entendimento.

No decorrer do processo de arbitragem, existe ainda a possibilidade de as partes se manifestarem quanto ao conflito, e se isso ocorrer a comissão estabelecida analisará o acordo quanto à obediência de sua forma legal, podendo homologá-lo se correto.

Já na segunda hipótese, a arbitragem é considerada procedimento administrativo, com um rito semelhante. A decisão também será proferida por um corpo colegiado formado por três superintendentes da agência - o superintendente de comunicação e massa, o superintendente de serviços privados e o superintendente de serviços públicos -, sendo o presidente do processo de arbitragem aquele que não tiver jurisdição sobre as partes envolvidas.

Apesar de verificada a diferença do instituto da arbitragem em relação ao instituto do procedimento da ANATEL, nada impede que as empresas concessionárias façam incluir em seus contratos uma cláusula arbitral para dirimir seus litígios em fórum privado, o que significaria a eleição das partes pela arbitragem civil sem interferência da ANATEL.

\section{A PROBLEMÁTICA DOS ACORDOS DE INTERCONEXÃO DE REDES NO BRASIL}

Interconexão de redes é a ligação entre redes de telecomunicação que viabiliza a comunicação dos usuários entre operadoras diferentes. Definida no RGI, artigo $3^{\circ}$, inciso V, caracteriza-se como uma "[...] ligação de Redes de Telecomunicações funcionalmente compatíveis, de modo que os usuários de serviços de uma das redes possam comunicar-se com Usuários de serviços de outra ou acessar serviços nela disponíveis”. Em termos práticos, é por meio dos contratos de interconexão entre concessionárias que os usuários dos serviços de uma

\footnotetext{
Destaca-se que a arbitragem é também utilizada para a resolução de conflitos que envolvam relações comerciais entre países. O instituto, inserido no contexto da sociedade da informação, ganhou forma online e se traduz por ser um procedimento arbitral conduzido, total ou parcialmente, por meios eletrônicos viabilizados pelo uso da internet. Essa nova ferramenta pode ser usada para solucionar conflitos surgidos a partir de relações originadas pela internet ou pelas tradicionais formas presenciais de contratação, não sendo a origem do conflito determinante para sua utilização. Esse procedimento permite que um terceiro, neutro, decida sobre a controvérsia, usando tecnologias online para assistir o seu desenvolvimento. No Brasil, são exemplos a Arbitranet, CLAMARB - Câmara Latino Americana de Mediação e Arbitragem e a CAD - Câmara de Arbitragem Digital, que oferecem procedimentos de mediação e arbitragem online.
}

Revista de Direito Brasileira | São Paulo, SP | v. 17 | n. 7 | p. 203 - 220 | Mai./Ago. 2017 
operadora de determinado Estado conseguem se comunicar com os usuários de outra (BORGES, 2003).

Desse modo, os usuários da rede de determinada operadora ficam "ilhados" em sua própria rede até que sua operadora (detentora da concessão estatal para operar os serviços de telecomunicações em determinada área) tenha conseguido interconectar-se à rede de outras operadoras. A concretização da interconexão com cada rede se dá por meio de pactos comerciais, técnicos e operacionais entre operadoras concessionárias do mesmo tipo de serviço público.

Procedimentalmente, os contratos de interconexão entre concessionárias seguem os artigos 41 e 42 do RGI. Caso não haja impasse, o acordo segue a livre negociação tendo eficácia a partir da homologação da ANATEL, que não a fará se verificar prejuízo à competição, sendo este, em tese, seu principal papel na defesa dos direitos dos usuários, considerados as pontas mais fracas do jogo econômico.

As concessionárias têm 60 dias para celebrar o contrato de interconexão, e as solicitações são apresentadas primeiramente à prestadora e, ato contínuo, informadas à ANATEL. As concessionárias têm 30 dias para fazer as alterações necessárias. O contrato será válido se, decorrido o prazo, não houver pedidos de reformulação das partes. Porém, se existir controvérsia, qualquer dos interessados pode requerer a intervenção da agência reguladora, que arbitrará as condições para o estabelecimento da interconexão, garantindo assim que não haja interrupção do serviço aos usuários (BORGES, 2003).

Os entraves nos contratos de interconexão de redes ocorrem quando a operadora que os requeiram tenha sua entrada em operação procrastinada pela operadora concedente. Isso acontece quando há discordância quanto ao valor das tarifas ${ }^{11}$ que a operadora entrante deve pagar à concedente pelo uso de sua infraestrutura (SILVA NETO, 2011), como ficará claro na apresentação do estudo de caso. Soma-se ao fato de ser a interconexão de redes necessária à prestação de serviço essencial ao desenvolvimento do país.

Por isso a LGT estabelece, no artigo 147, a obrigatoriedade da interconexão às redes de telecomunicações e suporte à prestação de serviços de interesse coletivo, impondo prazos nos termos da regulamentação da ANATEL para que os pactos comerciais sejam finalizados. No mesmo sentido, o artigo 28 do RGI reafirma a obrigatoriedade da interconexão entre as operadoras. Tais detalhes agregam ainda maior pressão às operadoras entrantes no sentido de encontrar uma solução rápida para atingir o fim das concessões públicas de prestação de serviços de telecomunicações (BORGES, 2003).

Os custos de interconexão representam uma parcela significativa no valor da prestação do serviço, no importe de $30 \%$ a $40 \%$ do custo total. Por isso, apesar de a regulamentação

\footnotetext{
11 O critério de aplicação e o valor da tarifa são determinados pela ANATEL, por se tratar de um serviço de telecomunicação essencial para o desenvolvimento do país. A interconexão foi definida no art. $3^{\circ}$, inciso VI do RGI, como a ligação entre redes de telecomunicações funcionalmente compatíveis, de modo que os usuários de serviço de uma das redes possam comunicar-se com os usuários de serviços de outra rede, ou acessar serviços nela disponíveis. As condições gerais para que ocorra a interconexão de redes são objeto de livre negociação entre os interessados, formalizados em um contrato, dentro dos limites da lei e do regulamento, estando impedidos de comportamentos prejudiciais à livre competição. A regra do serviço de telefonia local deveria funcionar com a aplicação do critério de equilíbrio entre as chamadas originadas e recebidas, sem a necessidade de remuneração de rede entre as operadoras, já que se equivaleriam proporcionalmente. O desequilíbrio ocorre quando as chamadas originadas e recebidas não coincidem, sendo necessário uma operadora remunerar a outra. Esse desequilíbrio é frequente, pois o modelo de interconexão brasileiro foi estruturado para comunicação de "voz", que é bidirecional e dura em média quatro minutos, e não de "dados" para a internet, que é unidirecional e dura em média 20 minutos, sendo este o primeiro fator que gera diversos litígios entre as operadoras. Porém, quando há um desequilíbrio, considerado aquele acima de $55 \%$ entre chamadas originadas e recebidas, uma operadora deve remunerar a outra pelo excedente, e é nesse momento que os acordos de interconexão são postos em prática gerando muitas discussões. Dados extraídos de: Portal UOL Mundo Digital. Entenda o que é interconexão. Disponível em: <http://noticias.uol.com.br/mundodigital/ultimas/ult1345u16.jhtm>. Acesso em: 12 jun.2016.
} 
existente ter procurado estabelecer regras para reduzir os conflitos durante o processo de negociação dos contratos de interconexão, esse assunto continua sendo o de maior divergência entre as operadoras (BORGES, 2003).

Nesse sentido, os contratos de interconexão, apesar de submetidos a uma série de legislações e normas administrativas, estão suscetíveis a questões de domínio de mercado e econômicas para que se estabeleçam. Ademais, ao que parece, o modelo de privatização do sistema Telebrás pautou-se na ideia de que as redes de telefonia seriam usadas mais para transmissão de voz do que para a circulação de dados (MUNDO DIGITAL, 2003).

Sob essa ótica, as contas entre operadoras ficariam equiparadas, uma vez que haveria um número similar entre as chamadas de uma e outra operadora, não havendo prejuízos para nenhuma delas em razão da utilização de ambas as infraestruturas. Porém não foi o que correu. Já nos primeiros anos do século XXI, o abrupto aumento do uso da internet alterou esse cenário de forma expressiva, gerando uma dificuldade contábil para as operadoras. A convergência entre transmissão de voz e circulação de dados é definida por Noll e Price (1998) como sendo uma sobreposição das capacidades de diferentes tecnologias de informação. A rede que antes só comportava tráfego de dados passou também a comportar tráfego de voz. Atualmente o computador permite a comunicação falada. Por outro lado, na rede em que antes só circulava voz agora trafegam também dados, o que possibilita o envio de mensagens de texto pelo celular (SANTOS, 2006).

$\mathrm{O}$ problema baseia-se no fato de determinado assinante pagar à operadora uma tarifa com base no STFC (Serviço Telefônico Fixo Comutado), isto é, um pulso a cada quatro minutos, enquanto as operadoras têm de remunerar tarifas de interconexão umas às outras por minuto. Deste modo, ao ter um provedor de internet gratuito em sua rede, determinada operadora pode receber muito mais chamadas do que originá-las, provocando o chamado "sumidouro de tráfego", causador do desequilíbrio contábil mencionado (MUNDO DIGITAL, 2003).

Ao estruturar o modelo de privatização do Sistema TELEBRAS, não se imaginava o crescimento no uso da internet da forma como ocorreu, ou pelo menos não houve o planejamento adequado para tanto, gerando problemas de ordem financeira e contábil para as operadoras e, a reboque, diversos conflitos de outra magnitude entre elas. $\mathrm{O}$ que de fato ocorre é que os consumidores pagam um pulso a cada quatro minutos para a operadora contratada, enquanto as operadoras devem pagar tarifas de interconexão umas às outras por minuto. Isso gera distorção considerável, pois a operadora local que oferece a infraestrutura de acesso local à internet paga 16 vezes mais tarifa de interconexão à outra operadora do que o valor recebido do assinante (MUNDO DIGITAL, 2003).

Segundo Lima e Azevedo (2014), uma possível solução seria o recálculo das tarifas entre operadoras quando da negociação dos contratos de interconexão. Porém esse recurso é matematicamente intrincado e encontra diversas fórmulas econômicas ainda não pacificadas. Ora porque o custo final recai sobre o consumidor, ora porque o valor da diferença recai sobre a operadora entrante. Ademais, é difícil o consenso entre as concessionárias porque os interesses econômicos são divergentes no momento das negociações.

\section{A ATUAÇÃO DA ANATEL NOS CONFLITOS E NEGOCIAÇÕES DE INTERCONEXÃO DE REDES}

No cenário nacional, é notório que as normas aplicáveis às telecomunicações incentivam a desconstrução amigável de conflitos entre as operadoras de serviços de telecomunicações, bem como atribuem à ANATEL o dever de tutelar os direitos dos usuários por meio do sistema administrativo de repressão às infrações, nos mesmos moldes do modelo ocidental europeu. Como visto, a LGT (artigo 19, XVII) atribui à ANATEL a função de compor administrativamente os conflitos de interesses entre prestadoras de serviço de telecomunicações, 
reprimindo infrações aos direitos dos usuários. Da mesma forma, os procedimentos de mediação e arbitragem estão previstos tanto no RI quanto no RGI da ANATEL. A agência reguladora ainda conta com a chamada Reclamação Administrativa, utilizada para evidenciar violação de direitos nos casos relativos à legislação de telecomunicações e que pode ter como partes prestadoras de serviços de telecomunicações e qualquer usuário.

A ANATEL, incumbida administrativamente de mediar, arbitrar e fiscalizar as distorções tarifárias entre as operadoras, tem a função, entre outras, de estabelecer como principal foco condutor das negociações o não repasse dos custos da internet gratuita (tarifa de interconexão) para a conta de seus assinantes, o que ensejaria o aumento generalizado da conta de telefone, garantindo com isso a efetividade da defesa dos direitos dos usuários.

No entanto, o que ocorre na prática é que todos os usuários de telefone, independentemente de utilizar ou não a internet, acabam pagando valores referentes à interconexão das operadoras, que por sua vez não conseguem chegar comercialmente a um consenso quanto ao responsável por esses custos.

Segundo o estudo de caso descrito na pesquisa de Cavalcanti e Martinelli, o marco inicial da discussão do problema no país refere-se à pendência entre a Telefônica e a Embratel no ano de 2003 (CAVALCANTI; MARTINELLI, 2003). Para que os clientes de telefonia local da Embratel pudessem se conectar com os clientes da Telefônica, e vice-versa, era necessário que as empresas estabelecessem um contrato de interconexão. Não obstante o fato de o provimento de interconexão ser obrigatório, suas condições são objeto de livre negociação entre as partes, formalizadas por contrato mediante acordo, e dependem da homologação da ANATEL para surtir efeitos. Porém, nesse caso, a livre negociação entre a Telefônica e Embratel ocorreu sem a formalização de um contrato, pois algumas questões comerciais impediram sua formalização, surgindo o conflito entre as empresas.

O embate ocorreu principalmente em razão das despesas pela utilização da infraestrutura da rede da Embratel pela Telefônica. Observa-se que as duas empresas tinham interesses comuns, pois a interconexão, sendo obrigatória, seria realizada independentemente da vontade das partes, conforme determinação da legislação aplicável. Porém, como as divergências se impuseram, criou-se um conflito incapaz de ser solucionado apenas pelas concessionárias.

$O$ processo de livre negociação entre as empresas teve a importante utilização da variável básica "informação", somada à do "poder do precedente" (CAVALCANTI, 2003), que dava à Embratel a certeza de que ocorreria a interconexão das redes, independentemente de acordo em razão da obrigatoriedade da interconexão - por se tratar de serviço público.

Segundo apurado na pesquisa de Melissa Franchini Cavalcanti (2003), a empresa Telefônica, pautada em uma interpretação jurídica do RGI, defendeu a tese de que a interconexão somente poderia ser implementada depois que o acordo comercial estivesse assinado, buscando a variável "informação" por meio de outra interpretação do regulamento e evitando a realização da interconexão sem um contrato assinado, já que as consequências lhe seriam financeiramente desfavoráveis. Nesse sentido, a argumentação que dava força à tese da empresa baseava-se no fato de que as regras de interconexão foram pensadas em uma época de tráfego equilibrado e que nos dias atuais o cliente de internet modificara a lógica da interconexão.

A Telefônica pretendia alcançar três milhões de clientes apenas com a internet e chamadas de longa duração (duração média de uma hora), que acontecem em geral nos fins de semana e à noite - chamadas que não têm a ligação de volta, modificando o sentido duplo da via e criando grande disparidade no fluxo de utilização da infraestrutura de uma concessionária para outra. Os impactos financeiros seriam grandes, pois nesse tipo de chamada a empresa recebe do cliente um pulso por chamada, pelo dia e hora em que são realizados, normalmente à noite e nos finais de semana (CAVALCANTI, 2003). Então, independentemente do tempo que o usuário utilizasse o serviço, a empresa pagaria um pulso de $\mathrm{R} \$ 0,08$ à época. E como a remuneração da interconexão era calculada por minuto, dentro desse conceito, na chamada de uma hora, a 
Telefônica receberia $\mathrm{R} \$ 0,08$ e teria de pagar $\mathrm{R} \$ 0,06$ de interconexão, multiplicado por 60 minutos e por $45 \%$, totalizando mais de $\mathrm{R} \$ 1,50$. Calculando uma chamada dessas por dia, a companhia teria uma perda de quase $\mathrm{R} \$ 50,00$ por mês para cada cliente (CAVALCANTI, 2003).

Nesse ponto fica claro uma das incongruências do modelo universal, isto é, da obrigação de o serviço ser prestado a todos, mesmo aos clientes menos rentáveis, sendo incompatível com o retorno do investimento privado. A Telefônica visualizava uma situação em que estava obrigada a aumentar as tarifas de todos os clientes para subsidiar aqueles que têm internet. A empresa argumentava à ANATEL e judicialmente que a questão, no caso a interconexão de voz-internet, fosse tratada diferenciadamente da tarifação do público receptor daquele, deste ou de ambos os serviços, alegando que o recente tráfego de internet é relevante para a apuração das tarifas de interconexão. Entretanto, as empresas não conseguiram atingir os resultados pretendidos nas duas esferas (CAVALCANTI, 2003).

Assim, formado o impasse, as empresas submeteram a questão à ANATEL, pois essa é uma das situações de conflito mencionadas na teoria, sendo imprescindível a atuação de uma "terceira parte" na mediação do conflito (CAVALCANTI, 2003). A ANATEL como "terceiro imparcial", seguindo o RGI, de início determinou que as partes, independentemente de acordo, fizessem a interconexão estabelecendo um prazo deliberatório. Observa-se que, em razão de seu papel, o órgão regulador tem o "poder de posição" (CAVALCANTI, 2003) para estabelecer que as partes assumam determinada responsabilidade diante da pendência, mesmo que não fosse momento da decisão final do processo de negociação, pois ainda não havia arbitrado a questão.

As empresas, portanto, tiveram que acertar um cronograma para a implementação da interconexão, isto é, o "tempo" resolutivo passou a ser negociado pelas empresas, pois estas sabiam que a interconexão ocorreria de qualquer forma. À época o caso foi objeto de grande especulação nos noticiosos, que em larga escala viam o acordo técnico de interconexão entre Embratel e Telefônica acontecer sob mediação da ANATEL (CAVALCANTI, 2003).

Em tal circunstância pode ser identificada a atuação da agência como mediadora da proposta técnica, acompanhando as reuniões entre as empresas tanto para garantir o atendimento do interesse público como para que o fator cronológico não fosse manipulado pelas empresas, também para que as redes permanecessem interconectadas de modo a não prejudicar a prestação de serviços. A intervenção nos acordos de interconexão tem justamente o objetivo de aproximar as partes, buscando decidir consensualmente as questões técnicas com a ANATEL - o "terceiro" imparcial e com especialidade no assunto em conflito.

Note-se, entretanto, que as questões comerciais permaneceram pendentes e nenhum contrato fora assinado, ocorrendo apenas a interconexão física, mas não a contratual. O conflito comercial, então submetido à arbitragem administrativa da ANATEL, conforme estabelece o RGI, teve seu processo correlato tramitando na agência por longo período, em contraposição à celeridade almejada via institutos de solução de conflitos alternativos ao judiciário, e sob esse aspecto o instrumento demonstrou-se ineficaz, não cumprindo ao fim a que se destina.

Nessa perspectiva, Cavalcanti e Martinelli (2004, p. 14) destacam a importância quanto à "obrigatoriedade legal de se atuar com ética, exigindo que o processo de solução de conflitos se situe no quadrante superior direito da "Matriz Lei/Ética" proposta por Lewicki e Hiam (2003)", isto é, para que haja efetividade dos preceitos normativos, os atores envolvidos no processo devem simultaneamente pautar suas ações no agir ético e de forma proativa. Também a postura do órgão regulador pode seguir esse princípio, buscando dar ao cenário dos conflitos em telecomunicações total transparência, e esse deveria ser seu objeto finalístico principal, o que não se verificou no caso em apreço, já que a morosidade no procedimento impediu que a solução fosse viabilizada com um procedimento alternativo. A interconexão ocorreu sem contrato comercial assinado, portanto, para evitar maiores prejuízos e um desempenho financeiro ruim, e a Telefônica, a parte que se sentiu lesada, apesar de conhecer a obrigatoriedade da interconexão, buscou alternativas para diminuir o impacto dos usuários de internet no processo dessa 
interconexão (FISHER; URY, 1985).

A alternativa encontrada pela concessionária entrante foi a fidelização das empresas de internet com relação à sua própria rede, direcionando parte da contribuição a elas. Assim, frente à ausência de solução, fora criado o e-Telefônica e realizado um acordo com a Associação Brasileira de Internet - ABRANET e com grande parte dos provedores para que permanecessem na rede da Telefônica, garantindo condições econômicas para a viabilização da internet gratuita. O caminho encontrado pela Telefônica teve custos financeiros, porém menores se comparados com o risco de uma não solução (CAVALCANTI, 2003).

O que se constata pelo estudo de caso é a pouca efetividade prática da ANATEL na aplicação de seus meios alternativos de solução de conflitos, já que a demora do órgão regulador em dirimir adequadamente a pendência obrigou a Telefônica a encontrar sozinha solução comercial que, apesar de não eliminar o problema, minimizou-o.

O cenário atual sobre a arbitragem administrativa a cargo da agência reguladora parece não ter sofrido alterações desde então, conforme apontam as pesquisas de Abraão Balbino e Silva (2011). Segundo o economista que procedeu minuciosa pesquisa sobre o assunto, a ANATEL conta com dezenas ${ }^{12}$ de processos de arbitragem que versam sobre a pactuação dos valores de interconexão entre operadoras, fator que demonstra a ineficácia não só das Resoluções da agência que regulam o tema, mas também do mecanismo da arbitragem na solução deste tipo de conflito. A morosidade deste processos é apontada pelo pesquisador como fator preponderante na decisão das operadoras em verter tais conflitos ao judiciário.

Decorridos mais de 13 anos do conflito em estudo, a ANATEL parece não ter conquistado grandes avanços quanto a sua atuação na resolução dos conflitos inerentes aos contratos de interconexão de redes de telecomunicações. Prova disso são os diversos casos que são levados pelas empresas concessionárias ao Poder Judiciário ${ }^{13}$, evidenciando a pouca efetividade de todo o arcabouço normativo acerca dos meios alternativos para a resolução de conflitos no âmbito da autarquia, principalmente nos contratos de interconexão de redes de telecomunicações.

\section{CONCLUSÃO}

As telecomunicações - atividade estratégica de um país - têm apresentado mudanças constantes, requerendo novas soluções jurídicas e econômicas necessárias ao acompanhamento da sociedade da informação. Tais mudanças surgem em um contexto de interesses complexos, exigindo negociações para a composição de acordos e contratos. A pesquisa realizada, assim como a análise por meio do estudo bibliográfico de caso, possibilitou compreender a atuação do órgão regulador nas negociações do setor de telefonia fixa, tendo como base o processo de negociação do acordo de interconexão entre a Embratel e a Telefônica.

Evidenciado o impacto gerado pelos poderes da ANATEL, que assegurou um bom

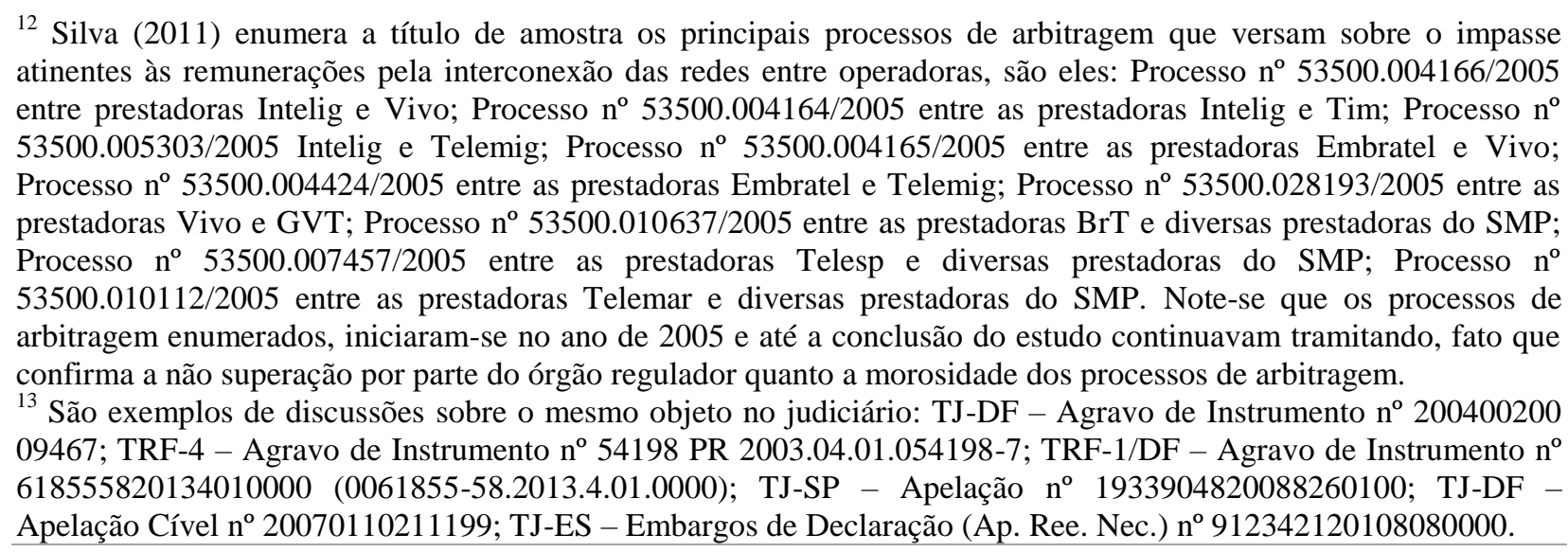

Revista de Direito Brasileira | São Paulo, SP | v. 17 | n. 7 | p. 203 - 220 | Mai./Ago. 2017 
desempenho nas negociações de caráter técnico, não há como desconsiderar que essa fora uma das primeiras experiências de âmbito regulatório e que a interconexão se realizou. $\mathrm{O}$ poder mediador da agência evidenciou-se, bem como sua capacidade de decidir e solucionar o conflito a ela submetido; também seu potencial fiscalizador, responsável por conduzir as partes a cumprir o pactuado após a decisão tomada com a mediação do poder regulador, que dispõe sobre as normas às quais estão submetidos as negociações e os conflitos.

A atuação da ANATEL ante o conflito comercial estabelecido entre as partes em comento, porém, demonstrou-se moroso e ineficiente, contrariando a razão de ser dos institutos de mediação e arbitragem. Tal tendência na solução de conflitos comerciais relacionados a questões de telefonia móvel e outros assuntos nos quais a interconexão é necessária para a disponibilização dos serviços essenciais de telecomunicações se seguiu nos anos subsequentes.

Ainda hoje, o órgão regulador recebe muitas críticas por não promover, como é sua atribuição, a flexibilização e democratização do setor, priorizando os interesses das operadoras e relegando a um segundo plano os interesses dos usuários. A demora é justificada pela agência em razão do quadro insatisfatório de pessoal e aos inúmeros procedimentos burocráticos que lhe são próprios. No entanto tal morosidade, além de prejudicial a pelo menos uma das partes, impõe alternativas muitas vezes insatisfatórias enquanto não se decide consensualmente o conflito, que também envolve a prestação de serviços essenciais à população, não podendo ficar pendentes ou à mercê de postergações. Além disso, como as decisões da ANATEL são jurídico-administrativas, isto é, podem ser questionadas judicialmente, há mais fatores a serem considerados quando o que está em jogo é a disponibilização de um serviço essencial.

Pretendeu-se com o presente artigo destacar a importância da ANATEL no modelo de flexibilização das telecomunicações no Brasil, apesar dos problemas elencados e analisados. Pelo que se verifica, há necessidade de modernização do órgão regulador no sentido de estruturá-lo para que os procedimentos de mediação e arbitragem administrativas se efetivem com maior eficiência e celeridade, atingindo assim sua finalidade maior, tendo em vista não só os interesses das empresas envolvidas no conflito, mas principalmente os dos usuários - destinatários finais e parte mais vulnerável dessas relações. Outro fator que merece atenção em estudos futuros diz respeito à maior participação da sociedade civil no cotidiano da ANATEL, que se efetivaria por meio de mecanismos já existentes como a consulta pública, visando ampliar o acesso às informações e decisões da agência - uma gestão calcada na transparência e na possibilidade de potencializar suas principais razões de ser: promover o amplo e irrestrito acesso e adaptar as telecomunicações no país a uma nova conjuntura social e política.

\section{REFERÊNCIAS BIBLIOGRÁFICAS}

ABREU, Miguel Cancella et al. A arbitragem voluntária e a mediação de conflitos. Coimbra (Portugal): Almedina, 2008.

ARAÚJO, E. N. Aparente Autonomia das Agências Reguladoras. In: MORAES, Alexandre de (Org.). Agências Reguladoras. São Paulo: Atlas, 2002. p. 39-58.

BARROCAS, Manuel Pereira. Lei de Arbitragem Comentada. Alfragide (Portugal): Leya, 2013.

BINENBOJM, Gustavo. Agências reguladoras independentes e democracia no Brasil. In: Revista Eletrônica de Direito Administrativo Econômico - REDAE, n. 3, ago./set./out. 2005, Salvador, Instituto de Direito Público da Bahia - IDPB. Disponível em: <www.direitodo estado.com/revista/REDAE-3-AGOSTO-2005-GUSTAVO\%20BINENBOJM.pdf>. Acesso em: 17 mar. 2017. 
BORGES, Miryan Natividade. Interconexão no Brasil. Tutorial de 26 maio 2003. Disponível em: <www.teleco.com.br/pdfs/tutorialinterc.pdf>. Acesso em: 17 mar. 2017.

BRASIL. Lei $n^{\circ}$ 9.472, de 16 de julho de 1997. Brasília: ANATEL, 2003.

BRASIL. Resolução n²70, de 19 de julho de 2001. Brasília: ANATEL, 2003.

BRASIL. Resolução $n^{\circ}$ 40, de 23 de julho de 1998. Brasília: ANATEL, 2003.

BRESSER PEREIRA, Luiz Carlos. Da administração pública burocrática à gerencial. In: Revista do Serviço Público, ano 47, n. 1, jan./abr. 1996. Disponível em: <www.bresserpereira. org.br/papers/1996/95.admpublicaburocraticaagerencial.pdf>. Acesso em: 17 mar. 2017.

CAVALCANTI, Melissa Franchini. A agência nacional de telecomunicações (ANATEL) e as negociações no setor de telefonia fixa. 2003. Dissertação de Mestrado - Faculdade de Economia, Administração e Contabilidade, Universidade de São Paulo - USP, São Paulo, 2003. Disponível em: 〈www.teses.usp.br/teses/disponiveis/12/12139/tde-30082004-143833/pt-br.php>. Acesso em: 17 mar. 2017.

; MARTINELLI, Dante Pinheiro. A atuação da Agência Nacional de Telecomunicações (ANATEL) no Acordo de Interconexão entre Embratel e Telefônica. Disponível em: <http://www.anpad.org.br/diversos/trabalhos/EnANPAD/enanpad_2004/ GPG/2004_GPG930.pdf>. Acesso em: 17 mar. 2017.

CELLI, Umberto Júnior. A nova organização dos serviços na lei geral de telecomunicações. In: Revista de Direito Administrativo, Rio de Janeiro, n. 211, p. 151-61, jan./mar. 1998.

CHIAVENATO, Idalberto. Introdução à teoria geral da administração: uma visão abrangente da moderna administração das organizações. ed. revisada e atualizada. Rio de Janeiro: Elsevier, 2003.

DASSO JÚNIOR, Aragon Érico. Estado regulador, regulação e agências reguladoras: uma contribuição teórica a partir do caso brasileiro. Disponível em: <www.derecho.usmp.edu.pe/ centro_derecho_economia/revista/febrero_2012/Estado_regulador_Aragon_Dasso_Junior.pdf $\rangle$. Acesso em: 17 mar. 2017.

DI PIETRO, Maria Sylvia Zanella. Direito Administrativo. São Paulo: Atlas, 2002.

FIORATI, Jete Jane. As telecomunicações nos direito interno e internacional: O direito brasileiro e as regras da OMC. Rio de Janeiro: Renovar, 2004.

FISHER, R; URY, W. Como Chegar ao Sim - A Negociação de Acordos sem Concessões. Rio de Janeiro: Imago, 1985. 
GUIMARÃES, Flavia Lefèvre. Incoerência e irresponsabilidade. In: Observatório de Imprensa, São Paulo, ed. 718, 30 out. 2012. Disponível em: <http://observatoriodaimprensa. com.br/interesse-publico/ed718-incoerencia-e-irresponsabilidade/ >. Acesso em: 17 mar. 2017.

LEWICKI, Roy J.; HIAM, Alexander. MBA Compacto - Estratégias de Negociação e Fechamento. Rio de Janeiro: Campus Elsevier, 2003.

LIMA, Lucas Ferreira Matos; AZEVEDO, Paulo Furquim de. Por que as tarifas de interconexão são tão altas? Um modelo de competição entre telefonia fixa e móvel. 42. Encontro Nacional de Economia, Natal (RN), 9-12 dez. 2014. Disponível em: <www. anpec.org.br/encontro/2014/submissao/files_I/i9-29ac5e3c33999149d6c476ca45a4813.docx>. Acesso em: 17 mar. 2017.

LINS, Bernardo Estellita. Privatização das Telecomunicações Brasileiras: Algumas Lições. Rio de Janeiro: Ipea, 2001.

MANEZELLO, Maria D'Assunção Costa. Agências Reguladoras e o Direito Brasileiro. São Paulo: Atlas, 2002.

MARQUES NETO, Floriano de Azevedo. Agência Reguladoras Independentes. Fundamentos e seu Regime Jurídico. Belo Horizonte: Fórum, 2005.

MARTINELLI, D. P.; ALMEIDA, A. P. Negociação-Como Transformar Confronto em

Cooperação. São Paulo: Atlas, 1997.

Negociação e Solução de Conflitos: Do impasse ao ganha-ganha através do melhor estilo. São Paulo: Atlas, 1998.

MATTOS, César. Políticas de assistência à entrada no setor de telecomunicações no Brasil: uma abordagem teórica. In: Revista Pesquisa e Planejamento Econômico - PPE, IPEA, Rio de Janeiro, v. 32, n. 1, abr. 2002. Disponível em: <http://ppe.ipea.gov.br/index.php/ppe/article /view/281/218>. Acesso em: 17 mar. 2017.

MAZZA, Alexandre. Agências Reguladoras. São Paulo: Malheiros, 2005.

MORAES, Alexandre de. Agência Reguladoras. In: MORAES, Alexandre de (Org.). Agências Reguladoras. São Paulo: Atlas, 2002.

MUNDO DIGITAL. Entenda o que é interconexão. Portal UOL, 16 jan. 2003. Disponível em: <http://noticias.uol.com.br/mundodigital/ultimas/ult1345ul6.jhtm>. Acesso em: 17 mar. 2017.

NOLL, Roger G.; PRICE, Monroe E. A Communications Cornucopia: Markle

Foundation Essays on Information Policy. Washington D.C.: Brookings 
Institution Press, 1998.

NOVAES, Ana. Privatização do setor de telecomunicações no Brasil. In: PINHEIRO, Armando Castelar; FUKASAKU, Kiichiro (Orgs.). A privatização no Brasil: $O$ caso dos serviços de utilidade pública. Rio de Janeiro, BNDES-OCDE, fev. 2000. p. 147-77. Disponível em: <http://www.provedor.nuca.ie.ufrj.br/eletrobras/estudos/novaes1.zip>. Acesso em: 17 mar. 2017.

PINTO, Luiz Roberto Nogueira. Arbitragem: a alternativa premente para descongestionar o Poder Judiciário. São Paulo: Arte \& Ciência, 2002.

SANTOS, Luciano Alves Rodrigues dos. A arbitragem no ordenamento jurídico brasileiro. São Paulo: Biblioteca 24x7, 2010.

SANTOS, Tatiana Braga Filippone. A reconfiguração da indústria de telecomunicações: A visão das operadoras de telefonia móvel operando no Brasil. 2006. Dissertação de Mestrado - Instituto COPPEAD de Administração, Universidade Federal do Rio de Janeiro - UFRJ, Rio de Janeiro, 2006. Disponível em: <http://www.coppead.ufrj.br/upload/publicacoes/Tatiana_ Santos.pdf>. Acesso em: 17 mar. 2017.

SILVA, Abraão Balbino e. Remuneração das redes de telefonia móvel no Brasil. 2011. Dissertação de Mestrado - Faculdade de Economia, Administração, Contabilidade e Ciência da Informação e Documentação, Universidade de Brasília - UnB, Brasília, 2011. Disponível em: <http://repositorio.unb.br/bitstream/10482/9260/1/2011_AbraaoBalbinoeSilva.pdf>. Acesso em: 17 mar. 2017.

SILVA NETO, José Borges da. Aspectos competitivos da interconexão em telecomunicações: o caso da telefonia móvel no Brasil. 2011. Dissertação de Mestrado - Faculdade de Economia, Administração e Contabilidade, Centro de Estudos em Regulação de Mercados, Universidade de Brasília - UnB, Brasília, 2011. Disponível em: <http://repositorio.unb.br/ bitstream/10482/9365/1/2011_JoseBorgesdaSilvaNeto.pdf>. Acesso em: 17 mar. 2017.

VARELLA, Guilherme. Regulação com participação popular: a peça que falta nas telecomunicações. IDEC - Instituto Brasileiro de Defesa do Consumidor. Disponível em: $<w w w$.idec.org.br/em-acao/artigo/regulaco-com-participaco-popular-a-peca-que-falta-nastelecomunicaces >. Acesso em: 17 mar. 2017.

VENTURA, Carla Aparecida Arena; MARTINELI, Dante Pinheiro. O papel das Agências Reguladoras na Gestão dos Serviços Públicos: Um estudo de caso da Agência Nacional de Telecomunicações - ANATEL. Trigésimo encontro da ANPAD, Salvador, 23-27 set. 2006, p. 114. Disponível em: <www.anpad.org.br/enanpad/2006/dwn/enanpad2006-apsa-2199.pdf>. Acesso em: 17 mar. 2017. 